\title{
Simulação de condição de fluxo em duto circular transportando polpa de bauxita de Paragominas (PA) na presença de aditivo modificador de viscosidade
}

\section{Simulation of flow condition in circular pipe transporting Paragominas bauxite slurry in the presence of a viscosity modifier}

\author{
Anny Caroliny Vidal de Lima Rodrigues ${ }^{1}$, Augusta Maria Paulain Ferreira Felipe ${ }^{1}$,
} José Antonio da Silva Souza ${ }^{1}$

\footnotetext{
${ }^{1}$ UFPA/ITEC/Programa de Pós-Graduação em Engenharia Química CEP: 66075 - 110, Belém, PA, Brasil. e-mail: annyquim@hotmail.com, ampf@ufpa.br, jass@ufpa.br
}

\section{RESUMO}

Sistemas de bombeamento de minérios por dutos tem atraído o interesse de mineradoras pois se tornam uma alternativa de transporte muito eficiente. Dentre os maiores desafios no projeto de bombeamento por dutos está a estimativa do fator de atrito, já que são muitas as variáveis que afetam este parâmetro. Uma amostra de polpa de bauxita de Paragominas (PA) a 52 \% (peso) que é bombeada por mineroduto foi caracterizada física, mineralógica e reologicamente. A polpa apresentou $d_{50}$ correspondente a $74 \mu \mathrm{m}$, massa específica 1455 $\mathrm{kg} / \mathrm{m}^{3}$, e viscosidade aparente 0,011 Pa.s. Sua composição mineralógica é essencialmente gibbsítica, contendo goethita, hematita, caulinita e anatásio. A curva de defloculação da polpa misturada ao hexametafosfato de sódio mostrou que o aditivo atuou como defloculante. A concentração de aditivo que promoveu viscosidade mínima da polpa corresponde a $250 \mathrm{~g}$ de aditivo/ tonelada de bauxita (em base seca). As polpas estudadas se adequaram ao modelo de Herschel-Bulkley. Através da equação de Dodge-Metzner, estimou-se o fator de atrito para polpas de bauxita sem aditivo e com aditivo na concentração ideal, que promoveu menor viscosidade, simulando as condições de fluxo utilizadas no mineroduto em Paragominas. Os resultados mostraram que o fator de atrito da polpa com aditivo apresentou redução de $12 \%$ em média quando comparado ao fator de atrito da polpa sem aditivo.

Palavras-chave: aditivo, bauxita, fator de atrito, viscosidade.

\begin{abstract}
Ore pumping systems flowing through pipelines has attracted the interest of mining companies as it might become a very efficient alternative of transport. Friction factor estimation is believed to be one of the greatest challenges in such projects because it is affected by many variables. A $52 \%(\mathrm{w} / \mathrm{w})$ Paragominas bauxite slurry sample was characterized according to its physical, mineralogical, and rheological properties. The properties of the sample were $74 \mu \mathrm{m} \mathrm{d}_{50}$ size, $1455 \mathrm{~kg} / \mathrm{m}^{3}$ specific gravity, and 0,011 Pa.s viscosity. Mineralogical composition of the sample was essentially bauxite, and it also contained other minerals such as goethite, hematite, kaolinite, anatase. Rheological tests revealed that the role of sodium hexametaphosphate was as deflocculant of the slurry. The concentration of the sodium hexametaphosphate in which viscosity values reached a minimum value was equivalent to $250 \mathrm{~g}$ of additive/ton of bauxite. The rheological behavior of bauxite samples studied was modeled according to Herschel-Bulkley equation. Friction factor of both samples with and without additive was estimated by applying Dodge-Metzner correlation, simulating the real flow conditions at the bauxite slurry pipeline in Paragominas. Results showed that friction factor values of samples containing additive reduced $12 \%$ average compared to the samples without any additive.
\end{abstract}

Keywords: additive, bauxite, friction factor, viscosity. 


\section{INTRODUÇÃO}

Na cidade de Paragominas, PA, está instalado o primeiro mineroduto de bauxita em operação do mundo. Este é considerado um empreendimento inovador no segmento e demanda estudos permanentes para garantir a eficiência do seu funcionamento bem como das operações, redução dos desperdícios $[1,2,3]$.

Esta alternativa de transporte pode ser muito viável para se transportar minérios extraídos em locais de difícil acesso, com pouca infraestrutura, distantes do ponto final, como é o caso do mineroduto de bauxita. Além disso, aspectos referentes à baixa geração de resíduos oriundos do transporte e baixo risco de acidentes durante o transporte são apontados como principais vantagens deste sistema de transporte de minérios ASIM [4].

A bauxita extraída em Paragominas está localizada no Platô Miltônia 3. A lavra consiste na remoção da camada vegetal e solo para extração da bauxita seguida de recomposição do solo. Na sequência, ocorre o beneficiamento composto por operações de britagem, moagem primária e deslamagem, moagem secundária, desaguamento e peneiramento final, recuperação da água de processo e disposição dos rejeitos. A bauxita em polpa segue através de um sistema de mineroduto até a cidade de Barcarena, onde está situada a refinaria de alumina BRUM [2].

Este sistema de mineroduto conta com instalações de preparo da polpa, bombeamento e desaguamento. Através do beneficiamento, frações argilosas são separadas da bauxita que, já cominuída, tem sua granulometria ajustada e é misturada à água na concentração adequada, seguindo para as estações de bombeamento que garantem o transporte via mineroduto até a estação de desaguamento, na cidade de Barcarena, para redução da umidade até $12 \%$ GANDHI [5].

O mineroduto em Paragominas tem $244 \mathrm{~km}$ de extensão, atravessa as cidades paraenses de Paragominas, Ipixuna do Pará, Tomé-Açu, Acará, Moju, Abaetetuba e Barcarena além dos rios Capim, Acará-Mirim, Acará e Moju, também no Pará. O material do duto é aço API-5L-X70 e tem 24 polegadas de diâmetro. Sua capacidade é 14,85 milhões de toneladas de bauxita por ano e possui duas estações intermediárias de bombeamento, que garantem a manutenção das condições operacionais ao longo do trajeto. A estação secundária conta com tanques de polpas e seis bombas de deslocamento positivo BRUM [2].

CUNNINGHAM [6] destaca como fatores a se considerar em um sistema de transporte por dutos: fonte de água, que deve estar localizada nas proximidades das instalações de preparo da polpa e o abastecimento deve ser contínuo; propriedades da polpa, como massa específica adequada para evitar consumo excessivo de energia na etapa de bombeamento, viscosidade e velocidade de escoamento para garantir que as partículas maiores não se depositem no fundo, prejudicando o fluxo; o projeto, que precisa levar em conta a resistência ao desgaste do material do duto, corrosão e existência de fendas internas além do dimensionamento de bombas, válvulas e automatização do sistema, entre outras questões.

Com intuito de se estimar as perdas relacionadas à fricção deste tipo de sistema de bombeamento, levantaram-se dados reológicos com intuito de simular uma condição semelhante à situação real de bombeamento de polpa de bauxita. Para o cálculo do fator de atrito, procedeu-se de acordo com a metodologia empregada por SILVA et al. [7] utilizando-se a correlação para o fator de atrito de DODGE e METZNER [8] e o número de Reynolds generalizado METZNER E REED [9] dados pelas Equações (1) e (2), respectivamente. Estas correlações têm sido empregadas para se estimar o fator de atrito de fluidos não newtonianos em regime turbulento, considerando-se escoamento completamente desenvolvido [10, 11].

$$
\begin{gathered}
\sqrt{\frac{1}{f}}=\frac{4}{n^{0,75}} \log \left[\operatorname{Re}_{g} f^{1-\frac{n}{2}}\right]-\frac{0,4}{n^{1,2}} \\
\operatorname{Re}_{g}=\frac{D^{n} V^{2-n} \rho}{8^{n-1} K\left(\frac{3 n+1}{4 n}\right)^{n}}
\end{gathered}
$$

Neste contexto, o presente trabalho buscou avaliar a eficiência do hexametafosfato de sódio como aditivo modificador de viscosidade da polpa de bauxita de Paragominas bem como sua eficácia na redução do fator de atrito de uma polpa de bauxita a partir da simulação de uma condição operacional semelhante àquela do mineroduto de bauxita de Paragominas. 


\section{MATERIAIS E MÉTODOS}

\subsection{Classificação granulométrica da bauxita}

A amostra de bauxita foi homogeneizada, quarteada a úmido e submetida ao peneiramento por via úmida empregando-se o conjunto de peneiras, série Tyler, de malhas 28\#, 32\#, 48\#, 65\#, 100\#, 150\#, 200\#, 325\# e 400\#. As frações $20 \mu \mathrm{m}, 10 \mu \mathrm{m}, 5 \mu \mathrm{m}$ e $2 \mu \mathrm{m}$ foram analisadas através de difração a laser por analisador de tamanho de partículas da Malvern Instruments, modelo Mastersizer 2000. Previamente à análise pelo granulômetro, a amostra é defloculada com hexametafosfato de sódio e homegeneizada em agitador magnético para garantir que as partículas permaneçam suspensas. A faixa de obscuração deve ser de $10 \%$ a $20 \%$. Estas análises foram realizadas no Laboratório Físico- Químico da Mineração Paragominas S.A. (MPSA).

\subsection{Concentração de sólidos e massa específica da polpa}

Para determinação da concentração de sólidos (Cs), pesou-se determinada massa de polpa em um béquer e secou-se o material em estufa a $105^{\circ} \mathrm{C}$ até peso constante. A massa específica foi medida pesando-se em uma proveta de $500 \mathrm{~mL}$ a massa de polpa correspondente a tal volume. A razão entre a massa e o volume de polpa correspondente define a massa específica do fluido.

\subsection{Caracterização mineralógica}

A caracterização mineralógica pelo método do pó foi realizada no difratômetro D8 Advance (Bruker) com geometria Bragg-Brentano e detector LynxEye, tubo de $\mathrm{Cu}\left(\mathrm{K} \alpha_{1}=1,540598 \AA\right.$ ), Filtro $\mathrm{K} \beta$ de Ni, fendas divergentes de $0,6 \mathrm{~mm}$, fenda Soller $\left(2,5^{\circ}\right)$, faixa angular de varredura $\left({ }^{\circ} 2 \theta\right) 5-75^{\circ}$, passo angular de $0,02^{\circ}$ e o tempo por passo $0.2 \mathrm{~s}$. A voltagem empregada foi $40 \mathrm{kV}$, corrente $40 \mathrm{~mA}$.

A análise dos difratogramas foi realizada pelo software HighScore Plus versão 3.0 e a identificação dos minerais foi realizada por meio de comparação entre os difratogramas obtidos e fichas padrões do banco de dados do ICDD-PDF (International Center for Diffraction Data - PowderDiffraction File).

\subsection{Testes reológicos}

Os testes reológicos foram realizados em viscosímetro HAAKE modelo VT550 com geometria cilindros concêntricos. Os experimentos foram conduzidos em temperatura ambiente. A programação das rotinas de trabalho foi estabelecida através do software Rheowin Job Manager 2.94 e o tratamento dos resultados foi feito empregando-se Rheowin Data Manager 2.94. Ressalta-se que este estudo não considerou o efeito do $\mathrm{pH}$ nas propriedades reológicas da polpa.

\subsection{Curva de defloculação}

O hexametafosfato de sódio foi dissolvido em água para obtenção das soluções nas seguintes concentrações $(\mathrm{m} / \mathrm{m}): 0,5 \% ; 1,0 \% ; 1,5 \% ; 2,0 \% ; 2,5 \% ; 3,0 \% ; 3,5 \%$. A polpa de bauxita a $50 \%(\mathrm{~m} / \mathrm{m})$ foi ensaiada na ausência e na presença do aditivo de modo que a cada ensaio misturava-se uma amostra de polpa à uma solução em concentração diferente. As condições do ensaio consistiram no emprego de taxa cisalhante de $100 \mathrm{~s}^{-1}$ durante $10 \mathrm{~s}$.

\subsection{Curva de fluxo}

Para determinar o comportamento reológico da polpa de bauxita, realizou-se o ensaio de curva de fluxo. Para minimizar os efeitos da sedimentação, empregou-se o método PSI descrito BRUM [2]. Foram avaliadas polpas a $50 \%(\mathrm{~m} / \mathrm{m})$ sem aditivo e polpas com aditivo na concentração que promoveu redução da viscosidade até um valor mínimo observado na curva de defloculação (concentração ideal de aditivo).

Os resultados da curva de fluxo foram ajustados pelo software do equipamento a um modelo reológico existente no banco de dados do próprio programa.

\subsection{Simulação e estimativa do fator de atrito}

O ajuste do comportamento das polpas a um modelo reológico fornece os parâmetros reológicos da suspensão. A metodologia para simulação do escoamento seguiu os critérios adotados por SILVA et al. [7] adaptados às condições deste experimento, que busca simular as condições reais de bombeamento de bauxita por mineroduto. Assim, o diâmetro e a vazão do duto correspondem aos parâmetros operacionais do próprio mi- 
neroduto de Paragominas $[2,5]$. A massa específica da polpa foi determinada experimentalmente.

Uma vez que são conhecidas todas as variáveis, estas são substituídas nas Equações (1) e (2) para estimar o fator de atrito. A Tabela (1) apresenta os parâmetros empregados na simulação do problema.

Tabela 1: Parâmetros do problema

\begin{tabular}{l|l}
\hline PARÂMETRO & VALOR \\
\hline Diâmetro $(\mathrm{m})$ & 0,6 \\
\hline Massa específica $\left(\mathrm{kg} / \mathrm{m}^{3}\right)$ & 1455 \\
\hline Faixa de vazão $\left(\mathrm{m}^{3} / \mathrm{s}\right)$ & 0,2 a 1 \\
\hline
\end{tabular}

\section{RESULTADOS E DISCUSSÃO}

\subsection{Caracterização da polpa}

A Figura (1) apresenta a distribuição granulométrica da polpa de bauxita de Paragominas.

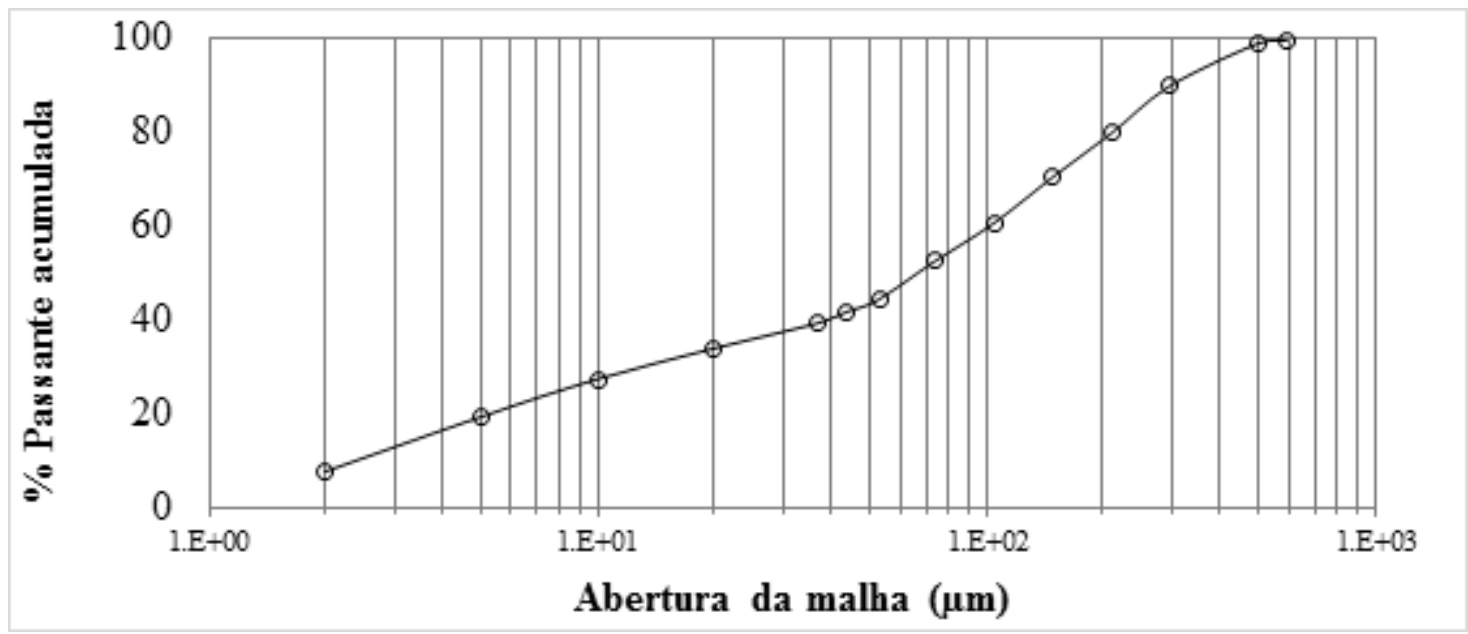

Figura 1: Distribuição granulométrica

A distribuição granulométrica mostra que a polpa de bauxita que é transportada por mineroduto é composta por $90 \%$ de suas partículas com tamanho inferior a $500 \mu \mathrm{m}, 10 \%$ abaixo de $5 \mu \mathrm{m}$. $\mathrm{O} \mathrm{d}_{50}$ da amostra correspondeu a $74 \mu \mathrm{m}$. Segundo classificação de OLIVEIRA e RUBIO [12], pode-se dizer que polpa de bauxita contêm partículas finas (tamanho menor que $100 \mu \mathrm{m}$ ), presentes em maior quantidade na amostra de polpa seguidas de partículas muito finas e ultrafinas.

SILVA [2] observou distribuição de tamanhos semelhante à apresentada na Figura (1) de uma amostra de bauxita de Paragominas após beneficiamento.

Os demais resultados referentes à caracterização física da polpa são apresentados na Tabela (2).

Tabela 2: Propriedades físicas da polpa de bauxita de Paragominas

\begin{tabular}{l|l|l}
\hline TEOR DE SÓLIDOS (\%) & $\begin{array}{l}\text { MASSA ESPECÍFICA } \\
\left(\mathbf{k g} / \mathbf{m}^{3}\right)\end{array}$ & $\begin{array}{l}\text { VISCOSIDADE APARENTE } \\
(\mathbf{P a . s})\end{array}$ \\
\hline 52 & 1455 & 0,011 \\
\hline
\end{tabular}

\subsection{Caracterização mineralógica}

A Figura (2) apresenta o difratograma da bauxita de Paragominas evidenciando os três picos principais refe- 
rentes às fases cristalinas presentes.

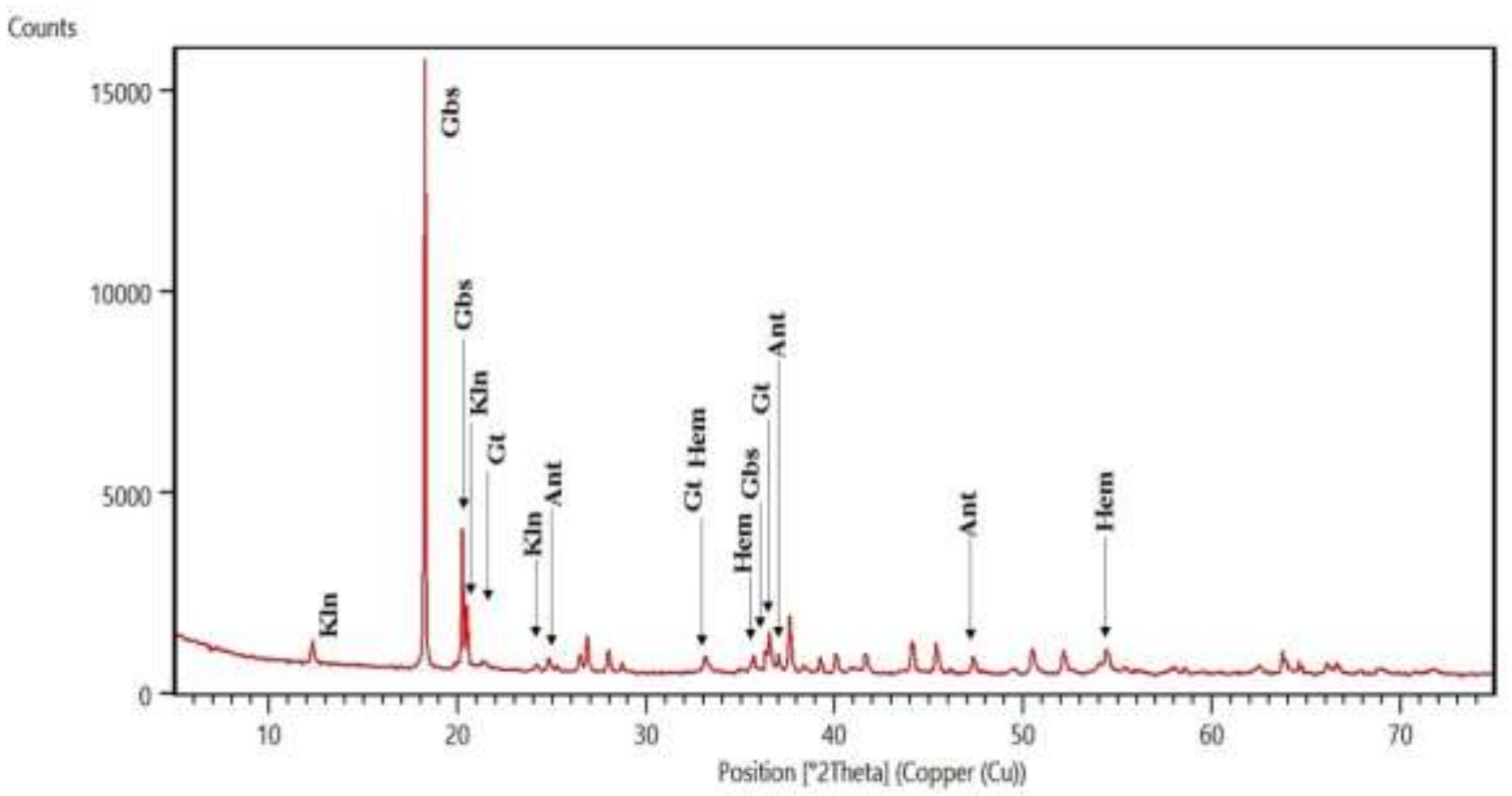

Figura 2: Difratograma da bauxita da Paragominas. Kln: caulinita; Gt: goehtita; Ant: anatásio; Hem: hematita colocar na legenda o que as siglas significam. E os demais picos observados?

A análise por DRX revelou que a bauxita de Paragominas é composta por gibbsita, contendo ainda óxidos de ferro (goethita, hematita), caulinita e anatásio. Não foram observadas nesta análise a presença de outros minerais. Este resultado está de acordo com estudos sobre a composição mineralógica da bauxita de Paragominas e caracterizações por DRX [13,14].

\subsection{Curva de defloculação}

A curva de defloculação da bauxita está representada através da Figura (3).

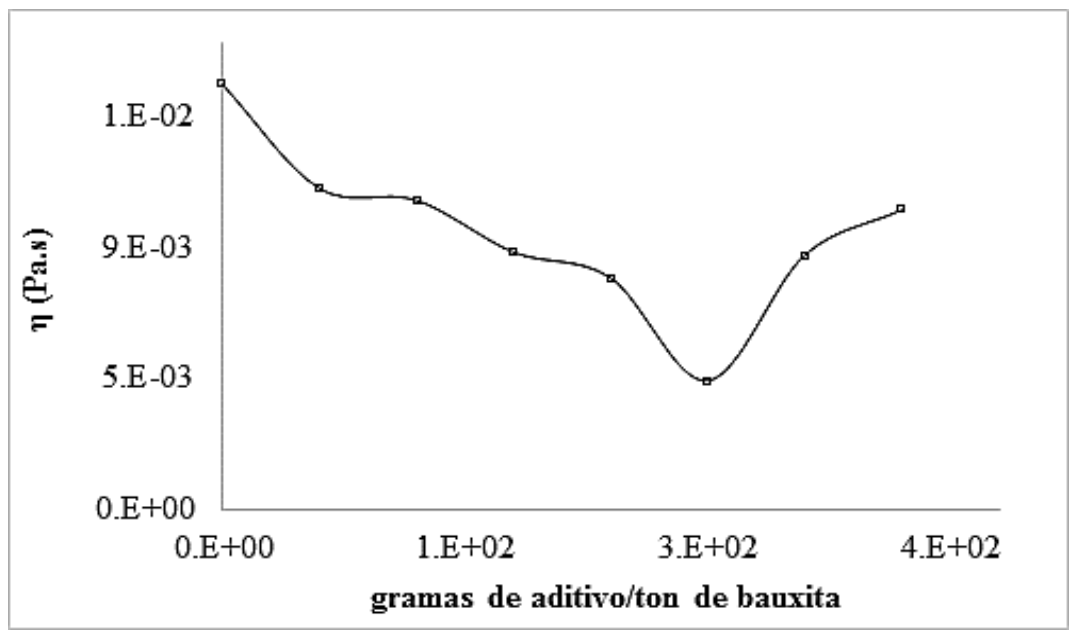

Figura 3: Curva de defloculação da polpa

Observa-se que à medida que se aumenta a concentração de hexametafosfato de sódio a viscosidade da polpa diminui até um valor mínimo. A concentração correspondente é chamada concentração ideal de defloculante e qualquer concentração de aditivo superior a ideal provoca um aumento significativo da viscosidade. 
A ação defloculante do hexametafosfato de sódio tem sido comprovada por meio de estudos prévios com rejeito de bauxita de Paragominas. Entretanto, na presença de $150 \mathrm{~g}$ de aditivo/tonelada de bauxita não foi observada mudança significativa na viscosidade da polpa de bauxita [15, 16]. Entretanto, AVILA et al., [17] ao determinar o grau de dispersão desta polpa na presença do hexametafosfato de sódio alcançaram a condição de $0,4 \%$ de aditivo e pH 5 como ótima.

\subsection{Curva de fluxo}

As curvas de fluxo da polpa sem aditivo e com aditivo assim como a curva obtida com os parâmetros ajustados são apresentadas na Figura (4).

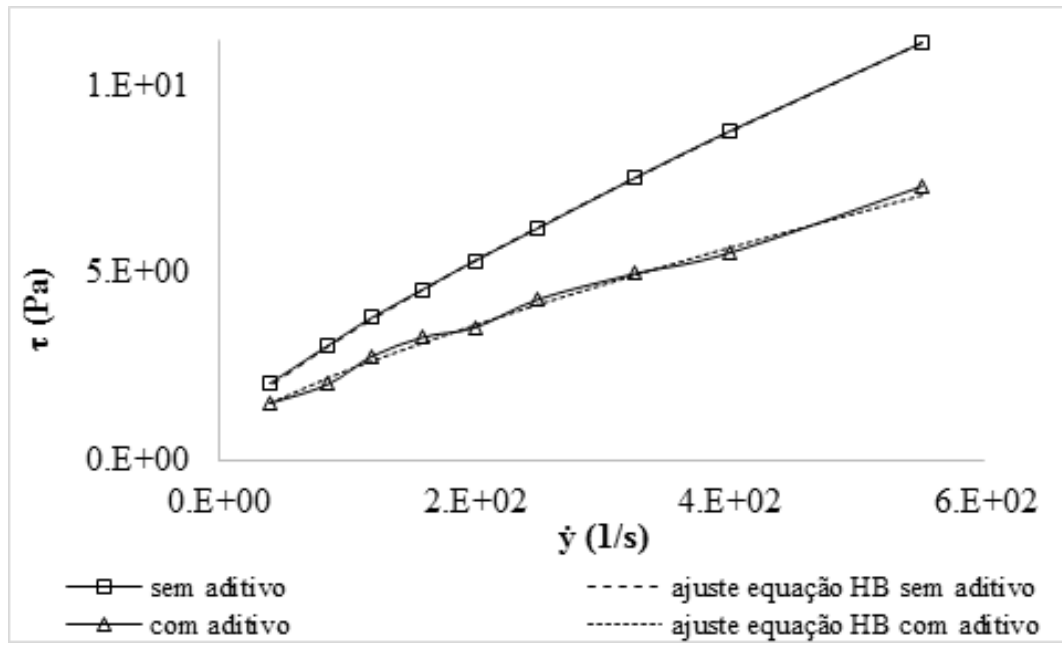

Figura 4: Curva de fluxo

As curvas de fluxo apresentadas na Figura (4) se ajustaram ao modelo reológico de Herschel-Bulkley de modo que a equação do modelo para a polpa sem aditivo e com aditivo substituindo-se os parâmetros obtidos pelo ajuste são dados pelas Equações (3) e (4). Os coeficientes de correlação foram 0,992 para a polpa sem aditivo e 0,981 para a polpa com aditivo. O ajuste ao modelo Herschel-Bulkley da polpa de bauxita a $50 \%$ de sólidos sem aditivo também foi obtido por BRUM [2] e polpas na presença de hexametafosfato foram observadas por SILVA [1].

Destaca-se a partir da Figura (4)

$$
\begin{gathered}
\tau=0,773+0,061 \times \gamma^{0,814} \\
\tau=0,701+0,049 \times \gamma^{0,771}
\end{gathered}
$$

Ainda da Figura (4) observa-se a ação defloculante do aditivo através da redução da tensão da polpa.

\subsection{Estimativas para cálculo do fator de atrito}

Substituindo-se os parâmetros das Equações (4) e (5) assim como os dados da Tabela (1) na Equação (2) para se determinar o número de Reynolds generalizado $\left(\mathrm{Re}_{\mathrm{g}}\right)$ e em seguida o fator de atrito (f) dado pela Equação (1), foram obtidos os resultados apresentados a seguir. A Figura (5) representa a relação entre o fator de atrito e a vazão volumétrica. 


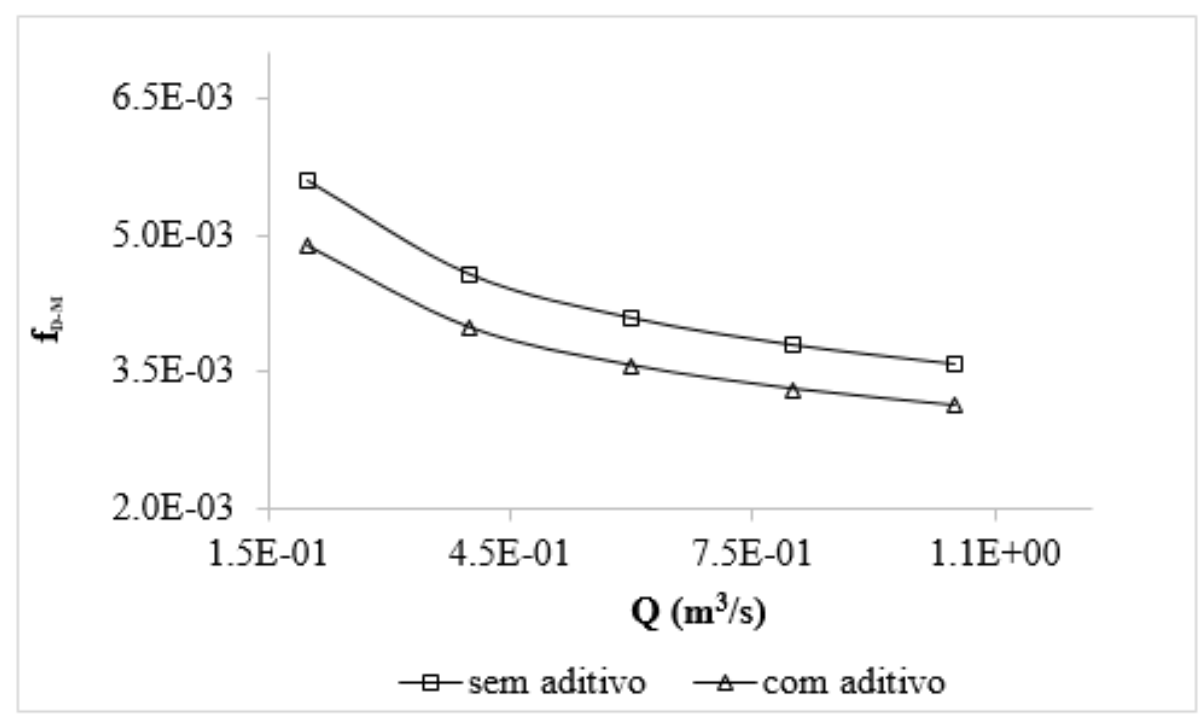

Figura 5: Gráfico Q vs $f$

A Figura (5) mostra que o fator de atrito dado pela Equação (1) diminui com o aumento da vazão volumétrica. Considerando-se que a vazão é diretamente proporcional à velocidade do escoamento e esta, por sua vez, é diretamente proporcional ao número de Reynolds generalizado apresentado na Equação (2), ao se estimar o fator de atrito f, a Equação (1) evidencia uma relação inversamente proporcional entre f e $\operatorname{Re}_{\mathrm{g}}$.

Ao comparar as curvas da Figura (5) observa-se que os fatores de atrito das polpas com aditivo se mostraram menores que $\mathrm{f}$ das polpas sem aditivo. Atribui-se este resultado à ação defloculante do hexametafosfato de sódio que favorece o fluxo das partículas no meio fluido devido à estabilização das mesmas. Em uma vazão correspondente à capacidade máxima do mineroduto, a simulação mostrou que o fator de atrito foi reduzido em cerca de $12 \%$ quando a polpa estava misturada ao aditivo na concentração ideal.

A relação entre o fator de atrito e o $\operatorname{Re}_{\mathrm{g}}$ é mostrada na Figura (6).

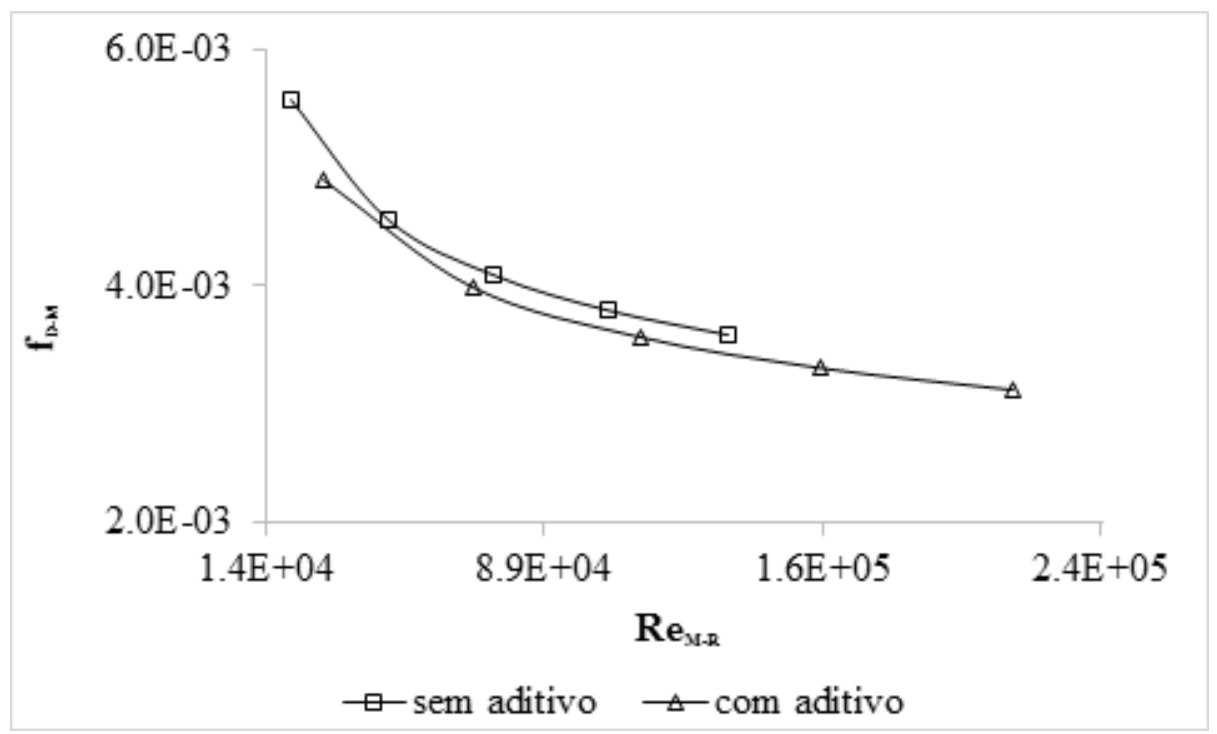

Figura 6: Gráfico $\operatorname{Re}_{\mathrm{g}}$ vs $\mathrm{f}$

A Figura (6) mostra que o fator de atrito dado pela Equação (1) diminui com o aumento de $\mathrm{Re}_{\mathrm{g}}$, e este mesmo comportamento foi mostrado por BRUM [2].

A partir da Figura (6), observa-se que, para um mesmo valor de número de Reynolds generalizado, a polpa com aditivo na concentração ideal apresenta menores valores de fator de atrito que a polpa sem aditivo. 
Novamente, atesta-se a eficiência do aditivo em favorecer as propriedades de fluxo da polpa de bauxita nas condições estudadas.

\section{CONCLUSÕES}

A bauxita de Paragominas é composta majoritariamente por gibbsita contendo também caulinita, goethita, hematita e anatásio. As polpas se ajustaram ao modelo reológico de Herschel-Bulkley e apresentaram comportamento dependente do tempo do tipo reopético.

O hexametafosfato de sódio atuou como defloculante na suspensão, diminuindo a tensão e a viscosidade das polpas. A concentração de aditivo que promoveu viscosidade mínima corresponde a $250 \mathrm{~g} / \mathrm{ton}$ de bauxita.

A simulação utilizada para se estimar o fator de atrito das polpas, tomando-se como referência condições operacionais do próprio mineroduto de bauxita, mostrou que o aditivo promoveu redução do fator de atrito de polpas de bauxita a $50 \%(\mathrm{~m} / \mathrm{m})$, parâmetro calculado pela correlação de Dodge-Metzner.

\section{AGRADECIMENTOS}

Os autores agradecem à CAPES e à MPSA/Norsk Hydro pelo apoio.

\section{BIBLIOGRAFIA}

[1] SILVA, K.C.S., Influência de aditivos químicos no comportamento reológico de polpa de bauxita, Dissertação de M. Sc., PPGEQ/UFPA, Belém, PA, Brasil, 2011.

[2] BRUM, S.M., Estudo da influência da granulometria no comportamento reológico de polpa de bauxita e no fator de atrito, Dissertação de M. Sc., - PPGEQ/UFPA, Belém, PA, Brasil, 2011.

[3] REIS, I.N.S.F. Influência da granulometria nas propriedades reológicas da polpa de bauxita pós beneficiamento, Dissertação de M. Sc., PPGEQ/UFPA, Belém, PA, Brasil, 2015.

[4] ASIM, T., MISHRA, R., PRADHAN, S., et al, “A Study on Optimal Sizing of Pipeline Transporting Equi-sized Particulate Solid-Liquid Mixture”, J. Phys.: Conf. Ser., v. 364, pp. 1-9, 2012.

[5] GANDHI, R., WESTON, M., TALAVERA, M., et al., "Design and operation of the world's first long distance bauxite slurry pipeline", In: Donaldson, D., Raahauge, B.E., (eds), Essential readings in light metals: alumina and bauxite, chapter 1, Hoboken, USA, John Wiley \& Sons, Inc, 2008.

[6] CUNNINGHAM, T., "Long-Distance Transport of Bauxite Slurry by Pipeline", Bechtel Technology Journal, v. 1, n. 1, pp. 1-12, 2008.

[7] SILVA, A.L.M.F., MESQUITA, A.L.A, FELIPE, A.M.P.F., et al., "Simulação do fator de atrito para o escoamento de caulim com diferentes teores de sólidos pelo modelo de SWAMEE-JAIN", Revista Matéria, v.22, n.2, 2017.

[8] DODGE, D.W., METZNER, A.B., “Turbulent flow of non-newtonian systems”, AlChe Journal, v.5, n.2, pp. 189-204, 1959.

[9] METZNER, A., REED, J.C., "Flow of non-newtonian fluids correlation of the laminar, transition, and turbulent-flow regimes". AIChe Journal, v.1, n.4, pp. 434-440, 1955.

[10] MALIN, M.R., "Turbulent pipe flow of Herschel-Bulkley fluids”, Int. Comm. Heat Mass Transfer, v.25, n.3, pp. 321-330, 1998.

[11] QUARESMA, J.N.N., Relatório técnico projeto experimentos e simulação em escoamentos nãonewtonianos, Universidade Federal do Pará, Belém, 2007.

[12] OLIVEIRA, C., RUBIO, J., "Mecanismos, técnicas e aplicações da agregação no tratamento mineral e ambiental", In: Série Tecnologia Ambiental 60, CETEM/MCT, pp. 1-69, 2011.

[13] KOTSCHOUBEY, B., CALAF, J.M.C., LOBATO, A.C.C., et al., "Caracterização e gênese dos depósitos de bauxita da província bauxitífera de paragominas, noroeste da bacia do Grajaú, nordeste do Pará/oeste do Maranhão”. In: MARIANI, O.J., QUEIROZ, E.T., RAMOS, B.W. (eds), Caracterização de depósitos minerais em distritos mineiros da Amazônia, cap.11, Brasília, DF, BRASIL, [s.n.], 2005.

[14] PAZ, S.P.A., ANGÉLICA, R.S., KAHN, H., "Optimization of the reactive silica quantification method applied to Paragominas-type gibbsitic bauxites", International journal of mineral processing, v.160, n.2, pp. 121-126, 2017. 
[15] ARAÚJO, D.G., NASCIMENTO, C.R., "Efeito da aditivação nas propriedades reológicas e nas características de sedimentação da polpa de bauxita: I ensaios preliminares", In: Jornada de iniciação científica, 16, pp. 22-28, Rio de Janeiro, 2008.

[16] GONÇALVES, S.G., FERREIRA, K.C., BRUM, S.M., et al., "Efeito de aditivos no comportamento reológico do rejeito da bauxita", Cerâmica, v.61, n.357, pp.1-5, 2015.

[17] AVILA, A. M. V.O., FLORES, T., PEREIRA Y. C., et al., "Otimização da dispersão de bauxita”. In: Painel PEMM, pp. 1-2, Rio de Janeiro, 2012.

[18] ARAÚJO, D.G., NASCIMENTO, C.R., "Propriedades reológicas da polpa de bauxita- II avaliação do rotor tipo vane", In: Jornada de iniciação científica, 15, pp.1-7, Rio de Janeiro, 2007.

\section{ORCID}

Anny Caroliny Vidal de Lima Rodrigues Augusta Maria Paulain Ferreira Felipe José Antonio da Silva Souza https://orcid.org/0000-0003-1355-8196

https://orcid.org/0000-0001-8384-9015

https://orcid.org/0000-0002-1784-9217 